\title{
The effect of asymmetries on stock index return value-at-risk estimates
}

Article

Accepted Version

Brooks, C. and Persand, G. (2003) The effect of asymmetries on stock index return value-at-risk estimates. Journal of Risk Finance, 4 (2). pp. 29-42. ISSN 1526-5943 doi: https://doi.org/10.1108/eb022959 Available at https://centaur.reading.ac.uk/21315/

It is advisable to refer to the publisher's version if you intend to cite from the work. See Guidance on citing.

To link to this article DOI: http://dx.doi.org/10.1108/eb022959

Publisher: Emerald

Publisher statement: This article is (c) Emerald Group Publishing and permission has been granted for this version to appear here (centaur.reading.ac.uk). Emerald does not grant permission for this article to be further copied/distributed or hosted elsewhere without the express permission from Emerald Group Publishing Limited. The definitive version can be found at:

http://www.emeraldinsight.com/journals.htm?articleid=1659769

All outputs in CentAUR are protected by Intellectual Property Rights law, including copyright law. Copyright and IPR is retained by the creators or other copyright holders. Terms and conditions for use of this material are defined in the End User Agreement. 


\section{CentAUR}

Central Archive at the University of Reading

Reading's research outputs online 
This article is (c) Emerald Group Publishing and permission has been granted for this version to appear here (centaur.reading.ac.uk). Emerald does not grant permission for this article to be further copied/distributed or hosted elsewhere without the express permission from Emerald Group Publishing Limited. The definitive version can be found at:

http://www.emeraldinsight.com/journals.htm?articleid=1659769 


\title{
The Effect of Asymmetries on Stock Index Return Value at Risk Estimates
}

\author{
Chris Brooks and Gita Persand ${ }^{1}$
}

\begin{abstract}
There is much evidence in the literature that the volatilities of equity returns show evidence of asymmetric responses to good and bad news. At the same time, there is evidence that the unconditional distribution of stock returns is asymmetric as well. This paper examines the effects of asymmetries of various forms on the accuracy of value at risk models. We compare the value at risk estimates derived from models which assume both a symmetric unconditional distribution of returns and a symmetric response of volatility to good and bad news, with models which explicitly allow for each class of asymmetries. We find that, between the two types of asymmetry considered, the asymmetry in the unconditional distribution is the more important feature. Use of the semi-variance, which allows for this feature, is shown to provide more stable and more reliable value at risk estimates than simple and more complex models that do not.
\end{abstract}

May 2002

Keywords: Stock index, Minimum Capital Risk Requirements, Internal Risk Management Models, Value at risk, asymmetries, multivariate GARCH, semi-variance

JEL Classifications: C14, C15, G13

\footnotetext{
${ }^{1}$ Chris Brooks (Corresponding author) ISMA Centre, University of Reading, Whiteknights Park, PO Box 242, Reading, RG6 6BA. Tel: +44 (0) 118931 6768; Fax: +44 (0) 118931 4741; E-mail C.Brooks@ismacentre.reading.ac.uk and Gita Persand, Department of Economics, University of Bristol. The authors would like to thank without implication Philippe Jorion, Editor of this journal, and an anonymous referee, for comments that considerably improved the quality of this paper.
} 


\section{Introduction}

There is widespread agreement in the relevant literature that equity return volatility rises more following negative than positive shocks. Pagan and Schwert (1990), Nelson (1991), Campbell and Hentschel (1992), Engle and Ng (1993), Glosten, Jagannathan and Runkle (1993), and Henry (1998), for example, all demonstrate the existence of asymmetric effects in stock index returns. There are broadly two potential explanations for such asymmetry in variance that have been suggested in this literature. The first is the "leverage effect", usually associated with Black (1976) and Christie (1982), which posits that if equity values fall, the firm's debt-to-equity ratio will rise, thus inducing equity holders to perceive the stream of future income accruing to their positions as being relatively more risky than previously. A second possible explanation for observed asymmetries is termed the "volatility feedback hypothesis". Assuming constant cashflows, if expected returns increase when stock price volatility increases, then stock prices should fall when volatility rises.

An entirely separate line of academic enquiry has centred around the determination of what is termed an institution's "value at risk (VaR)". VaR is a calculation of the likely losses that might occur from changes in the market prices of a particular securities or portfolio position. The minimum capital risk requirement (MCRR) or position risk requirement (PRR) is then defined as the minimum amount of capital required to absorb all but a pre-specified proportion of expected future losses. Dimson and Marsh (1995 and 1997) argue that portfolio-based approaches to determining PRRs are more efficient than alternative approaches, since the former allow fully and directly for the risk-reduction benefits from having a diversified book.

The number of studies in existence that seek to determine appropriate methods for calculating and evaluating value at risk methodologies has increased substantially in the past 5 years. Jackson et al. (1998) assess the empirical performance of various models for value at risk using historical returns from the actual portfolio of a large investment bank. Alexander and Leigh (1997) offer an analysis of the relative performance of equally weighted, exponentially weighted moving average (EWMA), and 
GARCH model forecasts of volatility, evaluated using traditional statistical and operational adequacy criteria. The GARCH model is found to be preferable to EWMA in terms of minimising the number of exceedences in a backtest, although the simple unweighted average is superior to both. The issue of sample length is discussed in Hoppe (1998), who argues that, for all asset classes and holding periods tested, the use of (unweighted) shorter samples of data yields more accurate VaRs than longer runs. Kupiec (1995), on the other hand, argues that long samples are always required in order to evaluate the effectiveness of those estimates using exception tests. Berkowitz (2002) also examines the frequency and the magnitude of "exceptions" (days when the VaR is insufficient to cover actual trading losses), although it is in the spirit of VaR modelling as per the Basle recommendations that only the number of exceptions is considered and not their sizes. Other recent studies that compare different models for computing VaR include those of Vlaar (2000), Longin (2000), Brooks et al. (2000), Lopez and Walter (2001) and Brooks and Persand (2000a, 2000b). Much research has relied upon an assumption of normally distributed returns, while in practice almost all asset return distributions are fat tailed. Two studies that have proposed methods to deal with leptokurtosis are Huisman et al. (1998) and Hull and White (1998).

This paper extends recent research and considers the effect of any asymmetries that may be present in the data on the evaluation and accuracy of value at risk estimates. A number of recent studies have examined the use of extreme value distributions for computing value at risk estimates. Such models can explicitly allow for leptokurtic return distributions, but can also account for asymmetries in the unconditional distributions by fitting separate models for the upper and lower tails. McNeil and Frey (2000), for example, propose a new method for estimating VaR based on a combination of GARCH modelling with extreme value distributions. Other papers employing EVT have included Longin (2000), Neftci (2000), and Brooks et al. (2002). However, since the extreme value theory (EVT) approach to computing position risk requirements has been considered elsewhere, we do not discuss it further here. Instead, we examine a number of alternative models that may be used to capture asymmetries in asset return distributions. Our analysis is conducted in the context of the stock markets 
of five Southeast Asian economies, and the S\&P 500 index, which is employed as a benchmark. We compare the performance of various models, some of which do, and some of which do not, allow for asymmetries. The models are evaluated in the context of the Basle Committee rules, and their proposed method for determining whether models for the calculation of $\mathrm{VaR}$ are adequate using a hold-out sample. To anticipate our main finding, we conclude that allowing for asymmetries can lead to improved VaR estimates, and that a simple asymmetric risk measure proves to be the most stable and reliable method for calculating $\mathrm{VaR}$.

The remainder of this paper is organised into six sections. Section 2 presents and describes the data employed, while the various symmetric and asymmetric volatility models utilised are displayed in section 3. Section 4 describes the methodology employed for the calculation of value at risk, while the value at risk estimates from the various models are presented and evaluated in section 5. Finally, section 6 offers some concluding remarks.

\section{Data}

The analysis undertaken in this paper is based on daily closing prices of five Southeast Asian stock market indices: the Hang Seng Price Index, Nikkei 225 Stock Average Price Index, Singapore Straits Times Price Index, South Korea SE Composite Price Index and Bangkok Book Club Price Index. We also employ the US S\&P 500 composite index returns as a benchmark for comparison. The data, obtained from Primark Datastream, run from 1 January 1985 to 29 April 1999, giving a total of 3737 observations. All subsequent analysis is performed on the daily log returns, with the summary statistics being given in Table 1. All six returns series exhibit the standard property of asset return data that they have 'fat-tailed' distributions as indicated by the significant coefficient of excess kurtosis. These characteristics are also shown by the highly significant Jarque-Bera normality test statistics. All series are also are either significantly skewed to the left (US, Hong Kong, and Singapore) or to the right (Japan, South Korea and Thailand). Unconditional skewness is an arguably important but neglected feature of many asset return series (see, for example, Harvey and Siddique, 
1999), which if ignored could lead to mis-specified risk management models. An illustration of where skewness may arise is given by the view that equity price movements "go up the stairs and down in the elevator", implying that upward movements are smaller but more frequent than downward movements, ceteris paribus. This being the case, a symmetrical measure such as variance will no longer be an appropriate measure of the total risk of an asset.

We also form, and perform subsequent analysis on, an equally weighted portfolio consisting of the five Southeast Asian market indices listed above. The advantage of diversification is clearly recognised in this case: the variance of the portfolio is only around one half of the variance of even the least volatile of the individual component series - see the penultimate column of Table 1. On the other hand, the distribution of portfolio returns is still skewed (to the left) and is leptokurtic. The skewness in all five series of returns data, and in the portfolio returns (albeit in different directions), is one manifestation of an asymmetry - in other words, this is prima facie evidence that the unconditional distribution of returns is not symmetric. We shall return to this feature of the data in the following section in the context of value at risk estimation.

\section{Symmetric and Asymmetric Volatility Models}

There exist a number of different methods for determining an institution's value at risk. The most popular methods can be usefully classified as being either parametric or non-parametric. In the former category comes the "volatilities and correlations approach" popularised by J.P.Morgan (1996); this method involves the estimation of a volatility parameter, and conditional upon an assumption of normality, the volatility estimate is multiplied by the appropriate critical value from the normal distribution and by the value of the asset or portfolio, to obtain an estimate of the VaR in money terms. There are broadly two ways that VaR could be calculated under the parametric umbrella. First, one could estimate a model for return volatility, and, conditioned upon this, employ the appropriate critical value from a relevant distribution. Second, one could, rather than estimating a conditional parametric model, employ the unconditional distribution of returns, fitting one of many other available 
parametric distributions. Press (1967) and Kon (1984), for example, both suggest the use of a mixture of normal distributions to explain the observed kurtosis and skewness in the distribution of stock returns. Madan and Seneta (1990), on the other hand, propose an entirely new class of models, known as variance-gamma processes, as a model for stock prices.

Non-parametric approaches to the calculation of value at risk can take many forms, but the simplest is derived from an estimate of the unconditional density of the sample of returns. So, for example, the VaR expressed as a proportion of the initial value of the asset or portfolio, which is required to cover $99 \%$ of expected losses, would simply be given by the absolute value of the first percentile of the return distribution. Jorion (1995) shows that the parametric approach to VaR can be preferable, even in situations where the returns are not normally distributed. In any case, non-parametric approaches are beyond the scope of this paper and are thus not considered further (but see, for example, Jorion, 1996, or Dowd, 1998, for extended descriptions of the various methods available under the nonparametric umbrella). Under the parametric approach, the normal distribution is employed almost universally, and the $\mathrm{VaR}$ (in money terms) for model $i$ is given by

$$
\operatorname{VAR}_{i}=\alpha\left(\mathrm{N}_{5 \%}\right) \sigma_{i} V
$$

where $\alpha\left(\mathrm{N}_{5 \%}\right)$ is the relevant value from the standard normal tables, $\sigma_{i}$ is the volatility estimate, and $V$ is the value of the portfolio. $\mathrm{VaR}$ is also commonly expressed as a proportion of the asset or portfolio value, and this convention will also be adopted in this study. Once a view is taken that a parametric approach will be employed for the calculation of $\mathrm{VaR}$, the issue simply boils down to estimation of the volatility parameter that describes the asset or portfolio ${ }^{2}$; we now present a variety of models which can be used for estimating and modelling $\sigma_{i}$.

\footnotetext{
${ }^{2}$ The models employed here are widely used and hence only brief model descriptions are given, although see Brailsford and Faff (1996) or Brooks (1998) for thorough discussions of alternative models for prediction of volatility and their relative forecasting performances under standard statistical evaluation metrics.
} 


\section{The Unconditional Variance}

An estimate of the unconditional variance provides the simplest method for forecasting future volatility, also known as an equally weighted moving average model, as forecasts are constructed by simply calculating the standard deviation from the most recent 3 years of historical data. This estimated historical standard deviation is then the prediction of the standard deviation over the evaluation period. The sample period is then rolled forward by 60 observations (one trading quarter), $\sigma_{i}$ re-estimated, and so on. To ensure consistency and a fair comparison, we also use the same framework (a 3-year rolling sample updated every 60 observations) to the estimation of the parameters for all other approaches employed.

We similarly employ the exponentially weighted moving average (EWMA) model, popularised by J.P. Morgan, and which has been found to produce accurate volatility forecasts. Under the EWMA specification, the fitted variance from the model, which becomes the forecast for multi-step ahead forecasts, is an exponentially declining function of previous squared values. The decay factor, " $\lambda$ ", is set to 0.94 following the J.P. Morgan recommendation and previous research in this area.

\section{The GARCH(1,1) Model}

Recent research (see Alexander and Leigh, 1997, for example), has suggested that GARCH-type models may be preferable for modelling volatility in a risk management context, and hence our conditional model analysis commences with the plain vanilla $\operatorname{GARCH}(1,1)$ model, given as follows:

$$
\begin{aligned}
& x_{t}=\mu+\varepsilon_{t} \\
& h_{t}=\gamma+\alpha \varepsilon_{t-1}^{2}+\beta h_{t-1}
\end{aligned}
$$

where, $x_{t}=\log \left(P_{t} / P_{t-1}\right)$ with $P_{t}$ being the value of the stock index at time $t$. And $\varepsilon_{t} \sim N\left(0, h_{t}\right)^{34}$. The volatility forecasts are constructed by iterating the conditional expectations operator in the usual

\footnotetext{
${ }^{3}$ The method of maximum likelihood using a Gaussian density and employing the BFGS algorithm is employed for estimation of the parameters of all models from the GARCH family, including the multivariate and asymmetric models.

${ }^{4}$ The model coefficient estimates for each model are not presented due to space constraints, although they are
} 
fashion.

To determine whether an asymmetric conditional volatility model is necessary and to ensure that the model does not under-predict or over-predict volatility in periods where there are large innovations in returns, the standardised residuals from the $\operatorname{GARCH}(1,1)$ specification are examined for sign and size bias, which is carried out using the tests of Engle and $\mathrm{Ng}$ (1993). The test for asymmetry in return volatility is given as follows:

$$
\frac{\varepsilon_{t}^{2}}{h_{t}}=\Phi_{0}+\Phi_{1} Z_{t-1}+\Phi_{2} Z_{t-1} \frac{\varepsilon_{t}}{\sqrt{h_{t}}}+\Phi_{3} Y_{t-1} \frac{\varepsilon_{t}}{\sqrt{h_{t}}}+\varpi_{t}
$$

where, $\varpi_{t}$ is a white noise disturbance term. $Z_{t-1}$ is defined as an indicator dummy that takes the

value 1 if $\frac{\varepsilon_{t}}{\sqrt{h_{t}}}<0$ and the value zero otherwise. $Y_{t-1}$ is defined as $1-Z_{t-1}$. Significance of the parameter $\Phi_{1}$ indicates the presence of sign bias whereas significant $\Phi_{2}$ or $\Phi_{3}$ would suggest size bias, i.e. not only the sign but the magnitude of innovation in $\frac{\varepsilon_{1}}{\sqrt{h_{t}}}$ is also important. A joint test for sign and size bias, based upon the Lagrange Multiplier Principle $T \cdot R^{2}$ may be performed as from the estimation of the above equation. The results of the tests are shown in Table 2, and suggest that the conditional volatility of the returns series may be sensitive to both the sign and size of shocks to volatility. Evidence for the presence of sign or size bias is presented for all countries (and the equally weighted portfolio), apart from South Korea.

\section{The GJR(1,1) Model}

The Threshold GARCH Model was suggested by Glosten, Jaganathan and Runkle (1993). The GJR(1,1) model utilises an additive modelling structure incorporating a dummy variable according to whether the previous innovation was positive or negative. The conditional variance $h_{t}$ is given by 


$$
h_{t}=\gamma+\alpha \varepsilon_{t-1}^{2}+\beta h_{t-1}+\lambda S_{t-1}^{-} \varepsilon_{t-1}^{2}
$$

where $S_{t-1}^{-}=1$ if $\varepsilon_{t-1}<0$ and $S_{t-1}^{-}=0$ otherwise

This simple modification of the $\operatorname{GARCH}(1,1)$ model can capture asymmetric consequences of positive and negative innovations. According to Glosten et al. (1993), if future variance is not only a function of the squared innovation to current return, then a simple $\operatorname{GARCH}(1,1)$ model is mis-specified and any empirical results based on that particular model are unreliable. The adjustment in the simple $\operatorname{GARCH}(1,1)$ model is such that the impact of $\varepsilon_{t-1}^{2}$ on the conditional variance $h_{t}$ is different when $\varepsilon_{t-1}$ is positive (i.e., the dummy variable takes a value of zero) than when $\varepsilon_{t-1}$ is negative (the dummy being one in this case). Glosten et al. (1993) found that negative residuals are associated with an increase in variance, while positive residuals are associated with a slight decrease in variance, conducive with the leverage argument and the volatility feedback hypothesis. The GJR coefficient estimates (not shown, but available upon request), show the asymmetry term, $\lambda$, to be significant at the $1 \%$ level for all countries except South Korea (where it is not significant even at the $10 \%$ level).

\section{The EGARCH Model}

The conditional variance of the exponential GARCH (EGARCH) model, suggested by Nelson (1991) to take into account the asymmetric response of volatility to positive and negative shocks in financial time series, is an alternative to the GJR formulation, and is expressed as

$$
\log \left(h_{t}\right)=\gamma+\beta \log \left(h_{t-1}\right)+\alpha \frac{\varepsilon_{t-1}}{\sqrt{h_{t-1}}}+\omega\left[\frac{\left|\varepsilon_{t-1}\right|}{\sqrt{h_{t-1}}}-\sqrt{\frac{2}{\pi}}\right]
$$

The asymmetric feature is taken into account by the $\alpha$ parameter. When $-1<\alpha<0$, a positive surprise increases volatility less than a negative surprise. When $\alpha<-1$, a positive surprise actually reduces volatility while a negative surprise increases volatility, whereas $\alpha=0$ leads to a positive surprise having the same effect on volatility as a negative surprise of the same magnitude. Empirical research has shown that $\alpha<0$, again corroborating the leverage and volatility feedback stories. Under this formulation, the asymmetry parameter is found to be significant for all countries and for 
the portfolio.

\section{Multivariate Models}

The next class of methods we propose to estimating value at risk, is based upon the multivariate GARCH, GJR and EGARCH models. This study employs the BEKK version of the multivariate GARCH model due Engle and Kroner (1995). This specification is a highly parsimonious quadratic form, and its development was motivated by the difficulty in checking and imposing the restriction that the variance-covariance matrix of residuals, $H_{t}$, be positive definite for general versions of the model, such as the vec specification or the diagonal model of Bollerslev, Engle and Wooldridge (1988). The matrix $H_{t}$ comprises the conditional variances on the leading diagonal, and the conditional covariances elsewhere. The $B E K K$ parameterisation may be expressed as

$$
H_{t}=C_{0}^{\prime} C_{0}+A_{1}^{\prime} \varepsilon_{t-1} \varepsilon_{t-1}^{\prime} A_{1}+B_{1}^{\prime} H_{t-1} B_{1}
$$

where $C_{0}, A_{1}$, and $B_{1}$ are parameter matrices to be estimated, $\varepsilon_{t-1}$ is a vector of lagged errors and

$$
C_{0}=\left[\begin{array}{l}
c_{11} \\
c_{12} \\
c_{13} \\
c_{14} \\
c_{15}
\end{array}\right] \quad A_{1}=\left[\begin{array}{lllll}
a_{11} & a_{12} & a_{13} & a_{14} & a_{15} \\
a_{21} & a_{22} & a_{23} & a_{24} & a_{25} \\
a_{31} & a_{32} & a_{33} & a_{34} & a_{35} \\
a_{41} & a_{42} & a_{43} & a_{44} & a_{45} \\
a_{51} & a_{52} & a_{53} & a_{54} & a_{55}
\end{array}\right] \quad B_{1}=\left[\begin{array}{lllll}
b_{11} & b_{12} & b_{13} & b_{14} & b_{15} \\
b_{21} & b_{22} & b_{23} & b_{24} & b_{25} \\
b_{31} & b_{32} & b_{33} & b_{34} & b_{35} \\
b_{41} & b_{42} & b_{43} & b_{44} & b_{45} \\
b_{51} & b_{52} & b_{53} & b_{54} & b_{55}
\end{array}\right]
$$

The BEKK parameterisation requires estimation of only 55 free parameters in the conditional variance-covariance structure (compared with 255 in the completely unrestricted vec model), and guarantees $H_{t}$ positive definite. Simple modifications to (6) can be made to allow for asymmetries under the GJR and EGARCH formulations. The modified model including asymmetry terms in a quadratic form could be written

$$
H_{t}=C_{0}^{* \prime} C_{0}^{*}+A_{1}^{* \prime} \varepsilon_{t-1} \varepsilon_{t-1}^{\prime} A_{1}^{*}+B_{1}^{* \prime} H_{t-1} B_{1}^{*}+D_{1}^{* \prime} \xi_{t-1} \xi_{t-1}^{\prime} D_{1}^{*}
$$

where $\xi_{j, t}=\min \left\{\varepsilon_{t}, 0\right\}$ and $D_{1}$ is a $5 \times 5$ parameter matrix including all of the asymmetry coefficients. In all cases, the estimated asymmetry terms are significant at the 5\% level or better. 


\section{The Semi-Variance}

Markowitz portfolio theory (MPT), which underlies many theoretical models in finance, carries with it the explicit assumption that asset returns are jointly elliptically distributed. Such an assumption may be considered undesirable since it rules out the possibility of asymmetric return distributions. Risk in the MPT framework is measured in terms of "surprises" rather than in terms of losses or failure to achieve an expected or benchmark return. Such a description of risk does not tie in well with most investors' notions of what constitutes a risk.

Another approach to estimating a volatility parameter, which may be used in the present context, and which has been given broad theoretical consideration in an asset allocation framework, is the concept of the lower partial moment (LPM) - see, for example, Choobineh and Branting (1986), Harlow (1991), and Grootveld and Hallerbach (1999). The lower partial moment of order $\alpha$ around $\tau$ is defined as

$$
\operatorname{LPM}_{\alpha}(\tau ; X)=\int_{-\infty}^{\tau}(x-\tau)^{\alpha} d F(X)
$$

where $F(X)$ is the cumulative distribution function of the return $X$. Setting $\alpha=2$, and $\tau=\mu$ in equation (8) above defines the semi-variance of a random variable $X$ with mean $\mu$.

Following JP Morgan RiskMetrics, and many empirical studies, assuming ${ }^{5}$ that $\mu=0$, an asymptotically unbiased and strongly consistent estimator of the semi-variance for a sample of size $T$ is given by (see Josephy and Aczel, 1993) ${ }^{6}$

$$
\sigma_{-}^{2}=\frac{T_{-}}{\left(T_{-}-1\right)^{2}} \sum_{x_{t}<0} x_{t}^{2}
$$

where $T_{-}$denotes the number of terms for which $x_{t}<0$, defined as $T_{-}$, and the scaled semi-standard

\footnotetext{
${ }^{5}$ In fact, this assumption can be made without loss of generality, for a zero mean series $x_{t}: t=1, \ldots, T$ can be constructed by subtracting the mean of the series $\bar{x}$ from each observation $t$.

${ }^{6}$ In (9), this is scaled by $T_{-} /\left(T_{-}-1\right) \rightarrow 1$ as $T \rightarrow \infty$, to obtain a consistent (asymptotically unbiased) estimator.
} 
deviation which we employ for the computation of value at risk is given by the square root of (9).

The square root of (9) can thus replace directly the usual standard deviation in (1). The scaled semistandard deviation (the square root of (9)) can account for the unconditional skewness in the distribution of returns. Expressed in this way, we can still employ the standard normal critical value since we now implicitly assume that $x_{t}<0$ follows a half-normal distribution. If desired, the formula in (9) could be trivially modified to estimate the upper scaled semi-standard deviation, which would be of interest for calculating the VaR of a short position.

\section{Methodologies for Calculating and Evaluating the Value at Risk}

The regulatory environment under the Basle Committee Rules requires that VaR should be calculated as the higher of (i) the firm's previous day's value-at-risk measured according to the parameters given below and (ii) an average of the daily VaR measures on each of the preceding sixty business days, with the latter subjected to a multiplication factor. Value-at-Risk is to be computed on a daily basis over a minimum "holding period" of 10 days. However, shorter holding periods can be used but they have to be scaled up to ten days, and in general this is achieved using the square root of time rule. Moreover, VaR has to be estimated at the $99 \%$ probability level, using daily data over a minimum length of one year (250 trading days), with the estimates being updated at least every quarter. The rules do leave the bank a broad degree of flexibility in how the VaR is actually calculated. For example, the MCRR estimates can be updated more frequently than quarterly, a longer run of data than one trading year can be employed, and the BIS does not stipulate which model should be employed for the calculations. Changes in any of these factors could potentially result in large changes in the calculated MCRR, so it is important that all candidate models for the calculation of VaR be thoroughly evaluated.

The multiplication factor, which has a minimum value of 3, depends on the regulator's view of the quality of the bank's risk management system, and more precisely on the backtesting results of the 
models. Unsatisfactory results might see an increase in the multiplication factor of 3 , up to a maximum of 4 . The regulator performs an assessment of the soundness of the bank's procedure in the following way. Under-prediction of losses by VaR models (that is, the days on which the banks calculated value at risk is insufficient to cover the actual realised losses in its trading book) are termed 'exceptions'. Between 0 and 4 exceptions over the previous 250 days places the bank in the Green Zone; between 5 and 9, it is in the Yellow Zone; and when 10 or more exceptions are noted, the bank is in the Red Zone. When the bank is in the Yellow Zone, one would almost certainly expect the Regulatory Body to increase the multiplication factor, while if the firm falls into the Red Zone, it is likely to be no longer permitted to use the internal modelling approach. It will instead be required to revert back to the "Building Block" approach, which does not include a reduction in the MCRR for diversified books and which will almost certainly yield a much higher capital charge. It is thus important for the securities firm or bank, as well as its regulators, that its risk measurement procedures are sound.

The VaR for each individual index was estimated, using the simple 5\% "delta-normal" approach proposed in the literature, i.e.,

$$
\begin{aligned}
\text { VaR } & =\text { Marked position of asset } \\
& \times \text { Sensitivity to price movement } \\
& \times \text { Adverse price movement per day }
\end{aligned}
$$

The sensitivity to price movements is taken to be 1 since we study equities which are linear instruments; the adverse price move per day is equal to $(1.645 \times 3 \times \sigma)$ where $\sigma$ is the estimated standard deviation of the asset returns over the sample period. Note that we multiply the VaRs by the regulatory scaling factor of 3 , and we use the $5 \%$ one-sided normal critical value. Whilst the Basle rules require the use of a $1 \% \mathrm{VaR}$, we use a $5 \% \mathrm{VaR}$ since the use of $1 \%$ together with the scaling factor results in a VaR that is so large as to render the models virtually indistinguishable from one another. $\sigma$ is calculated on a length of 3 years of data (based on the above 7 mentioned models) and the sample is rolled over after each quarter (60 days). For our selected data sample, this leads to 46 
separate sub-samples and out-of-sample periods which can be used to evaluate the adequacy of the value at risk estimates.

Each model for VaR outlined above is estimated for the six series under investigation and for the portfolio of Southeast Asian equities. In the cases where a parametric model for the conditional covariances is not specified (the variance, the semi-variance, all univariate models) we estimate the portfolio returns and determine the VaR for the portfolio as a single series. Such an approach may usefully be termed the "full valuation" approach, since it involves a calculation of the returns, and therefore the full value of the portfolio, for each time period. These results for the portfolio calculated from a single column of portfolio returns will be displayed under the "univariate model" heading. For the multivariate GARCH models, we use a slightly different approach, which may be viewed as a modified version of the "volatilities and correlations" method. This approach makes use of Markowitz Portfolio Theory, whereby for an $\mathrm{N}$-asset portfolio, the value at risk can be calculated by using the following formula:

$$
V a R_{p}=\sqrt{\sum_{i=1}^{N} a_{i}^{2} V A R_{i}^{2}+2 \sum_{i=1}^{N} \sum_{j=1, i \neq j}^{N} a_{i} a_{j} \rho_{i j} V A R_{i} V A R_{j}}
$$

where, $V a R_{p}$ is the value at risk of the portfolio, $a_{i}$ are the weights given to each of the assets in the portfolio, $V a R_{i}$ are the values at risk of the individual series $A$ and $B$, and $\rho_{i j}$ is the estimated correlation between the returns to $i$ and $j$. Since under a multivariate GARCH approach, we have a specification, and can therefore generate forecasts for, the conditional covariances as well as the conditional variances, we make use of these in equation (11) above. Thus the VaRs for the individual assets and the correlations are estimated using the forecasts obtained from the multivariate GARCH, EGARCH and GJR models. Then the equally weighted portfolio VaR is constructed using (11) and labelled as "MGARCH", "MGJR" and "MEGARCH" for the multivariate GARCH, GJR and EGARCH models respectively and these results are displayed under the "multivariate model" heading. 


\section{Results of VaR Estimation and Evaluation}

The VaR estimates for each asset and for each model, are presented in Table 3. Comparing the VaR estimates across Southeast Asian countries, they are highest for Hong Kong and Thailand, and lowest for the U.S., Singapore and the portfolio; unsurprisingly, the countries with the highest VaR estimates were also those which had the highest unconditional variance of returns. For most models, the country with the least stable VaRs over time, shown by the larger standard deviation of VaR across the 46 windows, is South Korea, which did not have one of the highest average VaRs. Interestingly, the average of the VaR estimates for the S\&P is approximately half that of the portfolio of 5 Southeast Asian stock indices, and about one quarter to one third of that of the individual component indices.

Comparing the VaR estimates across models, on the whole the average VaRs are fairly similar. The unconditional variance and the semi-variance-based estimates and the multivariate EGARCH model seem to give the largest VaRs, while the simple GARCH models (both univariate and multivariate) which do not allow for asymmetries, give the lowest average VaRs across the 46 windows for all countries, except for the US, where the univariate symmetric GARCH VaRs are uncharacteristically high. For example, in the case of the equally weighted portfolio, the univariate $\operatorname{GARCH}(1,1)$ model yields an average daily VaR of around 3.2\%, while the semi-variance-based estimator provides an average VaR of just above 4\%. The least stable VaRs, evidenced by the highest standard deviation across the 46 windows, arise from the EGARCH models, in both their univariate and multivariate forms. By far the most stable VaRs over time for all countries and the portfolio, are those calculated using the semi-variance. The semi-variance-based VaRs have a standard deviation across windows of the order of one half that of other models, except for those based on the (symmetric) variance, which have only slightly higher variabilities across windows. In the context of the S\&P index returns, the semi-variance gives a mean $\mathrm{VaR}$ of $1.8 \%$, the lowest of any model. An example of the stability of the VaR based on the semi-variance compared with its competitors can be gleaned from Figure 1, which plots the estimated VaRs for the portfolio using the GARCH model and the semi-variance. Both the 
higher average value at risk estimate under the latter model, and its relative smoothness over time, are apparent. The stability of the semi-variance $\mathrm{VaR}$ estimates relative to those calculated using the variance is quite surprising. If the returns were iid normally distributed, the semi-variance VaR should have a larger sampling variability since it employs approximately half as many observations as for the variance (and the trailing samples used for the variance and semi-variance cover the same 3-year period). Yet the semi-variance VaRs are equally stable for Hong Kong and are more stable for all other series. Clearly, however, the return distributions are non-normal and in particular are asymmetric. It also appears to be the case that the lower halves of the distributions that are picked out by the semi-variance, are more stable over time than the upper tails, which are included in the variance calculations but not in the semi-variance.

Finally, comparing the univariate models with their corresponding multivariate counterparts, we note that in all cases, that is for returns to the individual indices and for the portfolio, allowing for timevarying co-movements between the series leads to slightly higher average VaRs which are considerably more stable over time.

One may suggest at first blush that an optimal model is one that gives the lowest average and the most stable VaR estimate over time. A low VaR would be deemed preferable for the obvious reason that a lower VaR implies that the firm should be required to tie up less of its capital in an unprofitable, liquid form, while a stable VaR would be appealing on the grounds that a highly variable VaR would make an assessment of the riskiness of the securities firm over the long term difficult. However, a more appropriate test of the adequacy of the VaR models is under an assessment of how they actually perform when used on a hold-out sample ("backtests" in the Basle Committee terminology). Regulators impose severe penalties on firms whose models generate more than an acceptable number of "exceedences" or "exceptions" (see section 4 above), and for this reason as well as to minimise the possibility of financial distress, it is in the firm's interests to ensure that its VaR models perform satisfactorily in backtests. Backtest results for each model and for each asset series are presented in 
Table 4. The mean and standard deviation of the percentage of days for which there was an exceedence in each of the 46 rolling samples of length 250 observations is given, together with the number of times where the firm's VaR was insufficient on enough days in the sample to place it in the Yellow or Red Zone. Again, first considering the results across countries, in general the estimated VaR models for Hong Kong and Singapore seem to be the least adequate, while those for the U.S., South Korea and for the portfolio seem to yield the fewest exceptions. Only the univariate GARCH model would have ever led a securities firm with positions in these equities into the Red Zone, with consequent disallowance of the internal model and increased capital charges. Of the 46 sample periods, the models for four of the five countries would have been in the Red Zone at least once - with the worst being Singapore and Thailand, where the firm would have been in the Red Zone for two periods.

Comparing the GARCH and multivariate GARCH models with their asymmetric counterparts, the latter seem to do somewhat better. The average proportion of exceedences is lower for the GJR and EGARCH models, especially the latter, than those conditional variance models that do not allow for asymmetries, for all countries. For example, the average percentage of exceedences in the case of Thailand is approximately 1.7 using the GARCH model, but only 1.2 and 0.3 for the GJR and EGARCH models respectively. Also, the multivariate models tend to fare better than their univariate counterparts, irrespective of whether the models are symmetric or asymmetric. This is particularly true in the portfolio context, where the model estimation approach uses the time-varying forecasts of the conditional covariances as well as the volatilities. For example, the univariate GARCH model has an average of exactly $1 \%$ exceedences, placing the firm in the Yellow zone on three occasions; the multivariate GARCH model, on the other hand, has an average percentage of exceedences of only $0.1 \%$, placing the firm in the Yellow Zone only once. In the case of the US stock returns, all models are deemed safe, with no ventures into either the Yellow or Red zones. This appears to arise from a fall in S\&P volatility during the out of sample periods compared with the start of the sample. For example, splitting the whole sample exactly in half, the S\&P variance in the second half is 
approximately $50 \%$ of that in the first half.

In terms of the Basle Committee criteria, the clear winner is the semi-variance based estimator, which, if it had been employed by a securities firm with long positions in any of these market indices or a portfolio of them, would never have been out of the Green Zone. Whilst this improved performance would not come costlessly to the firm, in the sense that the VaR from the semi-variance-based model is almost always the highest, the improvement in performance is considerable relative to the models which generated the next highest VaR levels (the asymmetric multivariate models). The usefulness of the measure based on the semi-variance is also shown in Figure 2, which presents the number of exceedences for the portfolio of stock returns, using this method and also the univariate GARCH model. As can be seen, the semi-variance produces, for most windows, a smaller number of exceedences in the 250 day hold-out samples, than the GARCH model. Moreover, comparing Figures 1 and 2, the numbers of GARCH model exceedences are greater when the GARCH model VaR calculations are considerably below those of the semi-variance estimator. This seems to suggest that the GARCH model at times underestimates the VaR relative to the semi-variance model and relative to the actual out-turn.

\section{Conclusions}

This paper sought to consider the effect of two classes of asymmetry on the size and adequacy of market-based value at risk estimates in the context of five Southeast Asian stock market indices, and an equally weighted portfolio comprising these indices, with S\&P 500 index returns examined for comparison. We found significant statistical evidence that both unconditional skewness and a conditionally asymmetric response of volatility to positive and negative returns were present in the data. We then examined a number of symmetric and asymmetric models for the determination of a securities firm's position risk requirement. Our primary finding was that the semi-variance model, which explicitly allows for asymmetry, leads to more stable VaRs which would be deemed more accurate under the Basle Committee rules, than models which do not allow for such asymmetries. In 
particular, VaR estimates based upon a simple modification to the usual semi-variance estimator were the only ones which would have left the firm with a margin of safety during every time period and for every asset.

Put another way, models that do not allow for asymmetries either in the unconditional return distribution or in the response of volatility to the sign of returns, lead to inappropriately small VaRs. Although the cost of capital is on average 1\%-20\% higher for the asymmetric models, we conjecture that the additional margin of safety is necessary and makes the additional cost worthwhile. Firms which fall into the Yellow Zone are likely to have their multiplication factor raised from 3 to 4 or 5, an increase of at least $33 \%$ in the required VaR. Firms which trip into the Red Zone would be forbidden from using an internal model, and would be required to revert to the building block approach which specifies a flat charge of $8 \%$ for equities. This would represent an approximate doubling of the required capital for the portfolios compared with that reported for the asymmetric models in Table 3 .

Skewness is a hitherto virtually neglected feature of financial asset return series, and it seems plausible that better value at risk estimates should arise from methodologies which are able to capture all of the stylised features that are undeniably present in the data. We propose that future research may seek to form a model which can capture the unconditional skewness in the data as well as volatility clustering, leverage effects, and unconditional kurtosis; one such model is the autoregressive conditional skewness formulation, recently proposed by Harvey and Siddique (1999), which, due to its infancy, is as yet untested in the risk management arena.

\section{References}

Alexander, C.O. and Leigh, C.T. (1997) On the Covariance Models used in Value at Risk Models, Journal of Derivatives, 4, 50-62

Beltratti, A. and Morana, C. (1999) Computing Value at Risk with High Frequency Data Journal of Empirical Finance 6(5), 431-455 
Berkowitz, J. (2002) The Accuracy of Density Forecasts in Risk Management Journal of Business and Economic Statistics forthcoming

Black, F. (1976) Studies in price volatility changes, Proceedings of the 1976 Meeting of the Business and Economics Statistics Section, American Statistical Association, 177-181

Bollerslev, T., Engle, R.F. and Wooldridge, J.M. (1988) A capital asset pricing model with timevarying covariances, Journal of Political Economy, 96, 116-31

Brailsford, T.J. and Faff, R.W. (1996) An Evaluation of Volatility Forecasting Techniques Journal of Banking and Finance 20, 419-438

Brooks, C. (1998) Forecasting Stock Return Volatility: Does Volume Help? Journal of Forecasting 17, 59-80

Brooks, C., Clare, A.D., and Persand, G. (2000) A Word of Caution on Calculating Market-Based Minimum Capital Risk Requirements Journal of Banking and Finance 14(10), 1557-1574

Brooks, C., Clare, A.D. and Persand, G. (2002) An Extreme Value Approach to Calculating Minimum Capital Risk Requirements Journal of Risk Finance 3(2), 22 - 33

Brooks, C. and Persand, G. (2000a) Value at Risk and Market Crashes Journal of Risk 2(4), 5-26

Brooks, C. and Persand, G. (2000b) The Pitfalls of VaR Estimates Risk 13(5), 63-66

Campbell, J. and Hentschel, L. (1992) No news is good news: An asymmetric model of changing volatility in stock returns, Journal of Financial Economics, 31, 281-318.

Christie, A. (1982) The stochastic behaviour of common stock variance: Value, leverage and interest rate effects, Journal of Financial Economics 10, 407-432.

Choobineh, F. and Branting, D. (1986) A Simple Approximation for Semivariance European Journal of Operational Research 27, 364-370

Dimson, E. and P. Marsh (1997) Stress Tests of Capital Requirements, Journal of Banking and Finance, 21, 1515-1546

Dimson, E., and P.Marsh (1995) Capital Requirements for Securities Firms, Journal of Finance, 50(3), $821-851$

Dowd, K. (1998) Beyond Value at Risk: The New Science of Risk Management Wiley, Chichester, UK

Engle, R.F and Kroner, K. (1995) Multivariate simultaneous generalised ARCH, Econometric Theory, 11, 122-150.

Engle, R.F. and Ng, V. (1993) Measuring and testing the impact of news on volatility, Journal of Finance, 48, 1749-1778.

Glosten, L.R., Jagannathan, R. and Runkle, D. (1993) On the relation between the expected value and the volatility of the nominal excess return on stocks, Journal of Finance, 48, 1779-1801. 
Grootveld, H. and Hallerbach, W. (1999) Variance vs Downside Risk: Is there really that much Difference? European Journal of Operational Research 114, 304-319

Harlow, W.V. (1991) Asset Allocation in a Downside-Risk Framework Financial Analysts Journal September-October, 28-40

Harvey, C.R. and Siddique, A. (1999) Autoregressive Conditional Skewness Journal of Financial and Quantitative Analysis 34(4), 465-487

Henry, Ó.T. (1998) Modelling the Asymmetry of Stock Market Volatility, Applied Financial Economics, 8, 145 - 153.

Hoppe, R., VAR and the Unreal World, Risk, 11(7), 45-50

Huisman, R., Koedijk, K.G., and Poqwnall, R.A.J. (1998) VaR-x: Fat Tails in Financial Risk Management Journal of Risk 1(1), 47-61

Hull, J. and White, A. (1998) Value at Risk when Daily Changes in Market Variables are not Normally Distributed Journal of Derivatives 5(3), 9-19

Jackson, P., Maude, D.J., and W. Perraudin (1998) Testing Value at Risk Approaches to Capital Adequacy, Bank of England Quarterly Bulletin, 38(3), 256-266

Jorion, P. (1996) Value at Risk: The New Benchmark for Controlling Market Risk, Chicago: Irwin.

Jorion, P. (1995) Big Bets Gone Bad: Derivatives and Bankruptcy in Orange County, San Diego: Academic Press

Josephy, N.H. and Aczel, A.D. (1993) A Statistically Optimal Estimator of Semivariance European Journal of Operational Research 67, 267-271

J.P. Morgan (1996) Riskmetrics Technical Document, 4th Edition.

Kon, S.J. (1984) Models of Stock Returns - A Comparison Journal of Finance 39, 147-165

Kupiec, P. (1995) Techniques for Verifying the Accuracy of Risk Measurement Models, Journal of Derivatives, 2, 73-84

Longin, F.M. (2000) From Value at Risk to Stress Testing: The Extreme Value Approach Journal of Banking and Finance 24(7), 1097-1130

Lopez, J.A. and Walter, C.A. (2001) Evaluating Covariance Matrix Forecasts in a Value at Risk Framework Journal of Risk 3, 69-98

Madan, D.B. and Seneta, E. (1990) The Variance Gamma (V.G.) Model for Share Market Returns Journal of Business 63, 511-524

McNeil, A.J. and Frey, R. (2000) Estimation of Tail-Related Risk Measures for Heteroscedastic Financial Time Series: An Extreme Value Approach Journal of Empirical Finance 7, 271-300

Neftci, S.N. (2000) Value at Risk Calculations, Extreme Events and Tail Estimation Journal of Derivatives 7(3), 23-37 
Nelson, D.B. (1991) Conditional Heteroskedasticity in Asset Returns: A New Approach Econometrica 59(2), 347-370

Pagan, A.R., and Schwert, G.W., (1990) Alternative Models for Conditional Stock Volatility, Journal of Econometrics, 45, 267-290

Press, S.J. (1967) A Compound Events Model for Security Prices Journal of Business 40, 317-335

Vlaar, P.J.G. (2000) Value at Risk Models for Dutch Bond Portfolios Journal of Banking and Finance 24, 1131-1154 
Table 1

Summary Statistics: Stock Index Returns for the Period 1 January 1985 - 29 April 1999 (3737 Observations)

\begin{tabular}{cccccc}
\hline Mean & Variance & Skewness & Kurtosis & $\begin{array}{c}\text { Normality } \\
\text { Test } \dagger\end{array}$ \\
\hline Jong Kong & 0.00077 & 0.00030 & $-2.27613^{*}$ & $51.96710^{*}$ & $422368^{*}$ \\
Singapore & 0.00019 & 0.00018 & $0.10919^{*}$ & $10.03701^{*}$ & $15643^{*}$ \\
South Korea & 0.00056 & 0.00027 & $0.42596^{*}$ & $5.55209^{*}$ & $4897^{*}$ \\
Thailand & 0.00042 & 0.00030 & $0.15243^{*}$ & $9.85702^{*}$ & $15095^{*}$ \\
Portfolio & 0.00046 & 0.00009 & $-0.62792^{*}$ & $14.59893^{*}$ & $33324^{*}$ \\
S\&P 500 & 0.00024 & 0.00010 & $-3.62493^{*}$ & $80.59497^{*}$ & $1019595^{*}$ \\
\hline
\end{tabular}

Notes: * denotes significance at the $1 \%$ level. $\dagger$ Bera-Jarque Normality Test. The portfolio is an equally weighted combination of the 5 Southeast Asian market returns.

Table 2

Engle and Ng (1993) Test for the GARCH(1,1) Model: Stock Index Returns for the Period 1 January 1985 - 29 April 1999 (3737 Observations)

\begin{tabular}{|c|c|c|c|c|c|}
\hline & \multicolumn{5}{|c|}{$\frac{\varepsilon_{t}^{2}}{h_{t}}=\Phi_{0}+\Phi_{1} Z_{t-1}+\Phi_{2} Z_{t-1} \frac{\varepsilon_{t}}{\sqrt{h_{t}}}+\Phi_{3} Y_{t-1} \frac{\varepsilon_{t}}{\sqrt{h_{t}}}+\varpi_{t}$} \\
\hline & $\Phi_{0}$ & $\Phi_{1}$ & $\Phi_{2}$ & $\Phi_{3}$ & $\chi^{2}(3)$ \\
\hline Hong Kong & $\begin{array}{c}0.913 \\
(0.138)^{* *}\end{array}$ & $\begin{array}{c}0.189 \\
(0.176)\end{array}$ & $\begin{array}{l}-0.128 \\
(0.103)\end{array}$ & $\begin{array}{l}-0.088 \\
(0.142)\end{array}$ & $10.141^{*}$ \\
\hline Japan & $\begin{array}{c}0.937 \\
(0.112)^{* *}\end{array}$ & $\begin{array}{l}-0.042 \\
(0.148)\end{array}$ & $\begin{array}{l}-0.304 \\
(0.095)^{* *}\end{array}$ & $\begin{array}{l}-0.151 \\
(0.117)\end{array}$ & $19.723 * *$ \\
\hline Singapore & $\begin{array}{c}0.705 \\
(0.145)^{* *}\end{array}$ & $\begin{array}{c}0.159 \\
(0.188)\end{array}$ & $\begin{array}{l}-0.429 \\
(0.119)^{* *}\end{array}$ & $\begin{array}{c}0.149 \\
(0.146)\end{array}$ & $20.342 * *$ \\
\hline South Korea & $\begin{array}{c}0.979 \\
(0.075)^{* *}\end{array}$ & $\begin{array}{c}0.082 \\
(0.100)\end{array}$ & $\begin{array}{l}0.061 \\
(0.072)\end{array}$ & $\begin{array}{l}-0.037 \\
(0.070)\end{array}$ & 1.991 \\
\hline Thailand & $\begin{array}{c}0.846 \\
(0.113)^{* *}\end{array}$ & $\begin{array}{c}0.322 \\
(0.108)^{* *}\end{array}$ & $\begin{array}{c}0.085 \\
(0.100)\end{array}$ & $\begin{array}{l}-0.018 \\
(0.108)\end{array}$ & $10.222 *$ \\
\hline Portfolio & $\begin{array}{c}1.085 \\
(0.110)^{* *}\end{array}$ & $\begin{array}{c}-0.168 \\
(0.151)\end{array}$ & $\begin{array}{l}-0.173 \\
(0.101)\end{array}$ & $\begin{array}{l}-0.179 \\
(0.115)\end{array}$ & $10.992 *$ \\
\hline S\&P 500 & $\begin{array}{c}0.960 \\
(0.115)^{* *}\end{array}$ & $\begin{array}{c}0.037 \\
(0.151)\end{array}$ & $\begin{array}{c}-0.222 \\
(0.093)^{*}\end{array}$ & $\begin{array}{l}-0.178 \\
(0.122)\end{array}$ & $17.590 * *$ \\
\hline
\end{tabular}

Notes: Standard errors are in parentheses; * and ** indicate significance at the 5\% and $1 \%$ levels respectively. The portfolio is an equally weighted combination of the 5 Southeast Asian market returns. 
Table 3

Value-at-Risk Estimates: Stock Index Returns for the Period 1 January 1985 - 29 April 1999 (3737 Observations)

\begin{tabular}{|c|c|c|c|c|c|c|c|}
\hline & Hong Kong & Japan & Singapore & S. Korea & Thailand & Portfolio & S\&P 500 \\
\hline \multicolumn{8}{|c|}{ Panel A: Symmetric Approaches } \\
\hline \multicolumn{8}{|l|}{ Variance } \\
\hline Mean & 0.07411 & 0.06019 & 0.05165 & 0.07002 & 0.07486 & 0.04005 & 0.02010 \\
\hline Std. Deviation & 0.01356 & 0.01878 & 0.01489 & 0.02584 & 0.01676 & 0.00991 & 0.00714 \\
\hline \multicolumn{8}{|l|}{ EWMA } \\
\hline Mean & 0.07483 & 0.06254 & 0.05851 & 0.07463 & 0.08288 & 0.04345 & 0.01841 \\
\hline Std. Deviation & 0.04858 & 0.03006 & 0.03903 & 0.03579 & 0.04316 & 0.02333 & 0.01174 \\
\hline \multicolumn{8}{|l|}{ GARCH } \\
\hline Mean & 0.07317 & 0.05534 & 0.04908 & 0.06793 & 0.07152 & 0.03208 & 0.05273 \\
\hline Std. Deviation & 0.03670 & 0.02792 & 0.02672 & 0.04318 & 0.04619 & 0.04023 & 0.03867 \\
\hline \multicolumn{8}{|l|}{ MGARCH } \\
\hline Mean & 0.07330 & 0.05904 & 0.05046 & 0.06728 & 0.07031 & 0.03536 & - \\
\hline \multirow[t]{2}{*}{ Std. Deviation } & 0.02089 & 0.01911 & 0.01630 & 0.02191 & 0.02862 & 0.02259 & \\
\hline & \multicolumn{5}{|c|}{ Panel B: Asymmetric Approaches } & & \\
\hline \multicolumn{8}{|l|}{ GJR } \\
\hline Mean & 0.07335 & 0.05618 & 0.05062 & 0.06805 & 0.07289 & 0.03493 & 0.02025 \\
\hline Std. Deviation & 0.03716 & 0.02766 & 0.02749 & 0.04842 & 0.04887 & 0.03931 & 0.00718 \\
\hline \multicolumn{8}{|l|}{ EGARCH } \\
\hline Mean & 0.07399 & 0.05923 & 0.05082 & 0.06953 & 0.07351 & 0.03823 & 0.01935 \\
\hline Std. Deviation & 0.05252 & 0.02709 & 0.08298 & 0.05331 & 0.05271 & 0.07184 & 0.00836 \\
\hline \multicolumn{8}{|l|}{ Semi-Variance } \\
\hline Mean & 0.07461 & 0.06025 & 0.05166 & 0.07009 & 0.07500 & 0.04030 & 0.01800 \\
\hline Std. Deviation & 0.01316 & 0.01142 & 0.01253 & 0.01963 & 0.01570 & 0.00742 & 0.00520 \\
\hline \multicolumn{8}{|l|}{ MGJR } \\
\hline Mean & 0.07397 & 0.06004 & 0.05094 & 0.06818 & 0.07349 & 0.03696 & - \\
\hline Std. Deviation & 0.02714 & 0.02265 & 0.01752 & 0.02354 & 0.03045 & 0.02809 & \\
\hline \multicolumn{8}{|l|}{ MEGARCH } \\
\hline Mean & 0.07401 & 0.06014 & 0.05100 & 0.07011 & 0.07414 & 0.03920 & - \\
\hline Std. Deviation & 0.04860 & 0.02610 & 0.02718 & 0.03047 & 0.03283 & 0.02881 & \\
\hline
\end{tabular}

Note: Model acronyms are as follows: variance - denotes VaR calculated using the historical standard deviation of returns; EWMA denotes the VaR calculated using the exponentially weighted moving average method; MGJR and MEGARCH denote the multivariate GJR and EGARCH models respectively; semi-variance denotes a VaR calculated using the scaled semi-standard deviation of (9). Cell entries refer to the average and standard deviation of the VaR across the 46 out of sample windows; VaR is expressed as a proportion of the initial value of the position. The portfolio is an equally weighted combination of the 5 Southeast Asian market returns. 
Table 4: Back-Testing (i.e. out of sample tests) of the VaR for Stock Index Returns January 1985 - 29 April 1999 (3737 Observations)

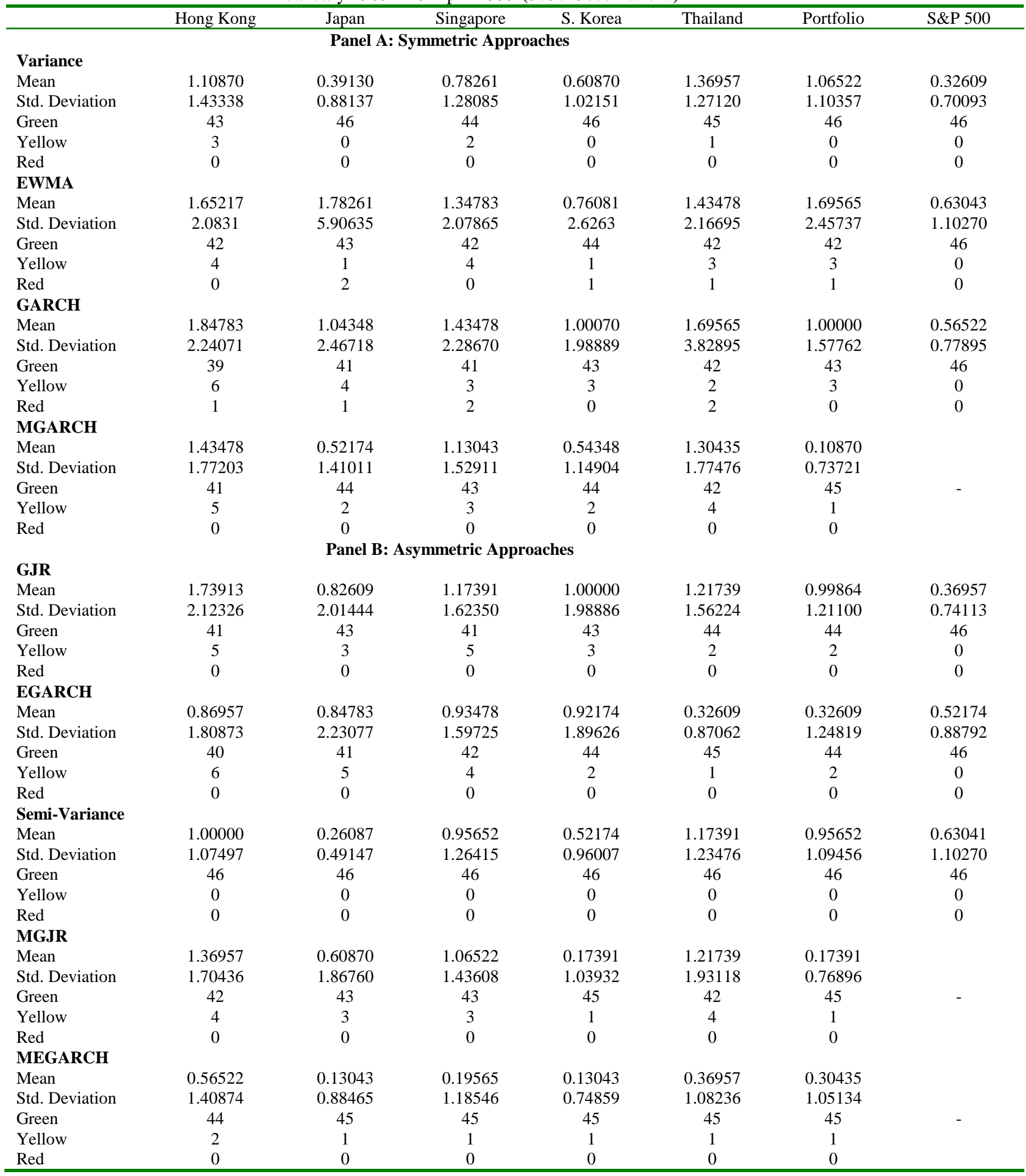

Notes: Note: Model acronyms are as follows: variance - denotes VaR calculated using the historical standard deviation of returns; EWMA denotes the VaR calculated using the exponentially weighted moving average method; MGJR and MEGARCH denote the multivariate GJR and EGARCH models respectively; semi-variance denotes a VaR calculated using the scaled semi-standard deviation of (9). Cell entries refer to the average and standard deviation of the number of exceedences of the VaR across the 46 out of sample windows, and the number of times that such a number of exceedences would have placed the firm in the Green, Yellow and Red zones; VaR is expressed as a proportion of the initial value of the position. The portfolio is an equally weighted combination of the 5 Southeast Asian market returns. 

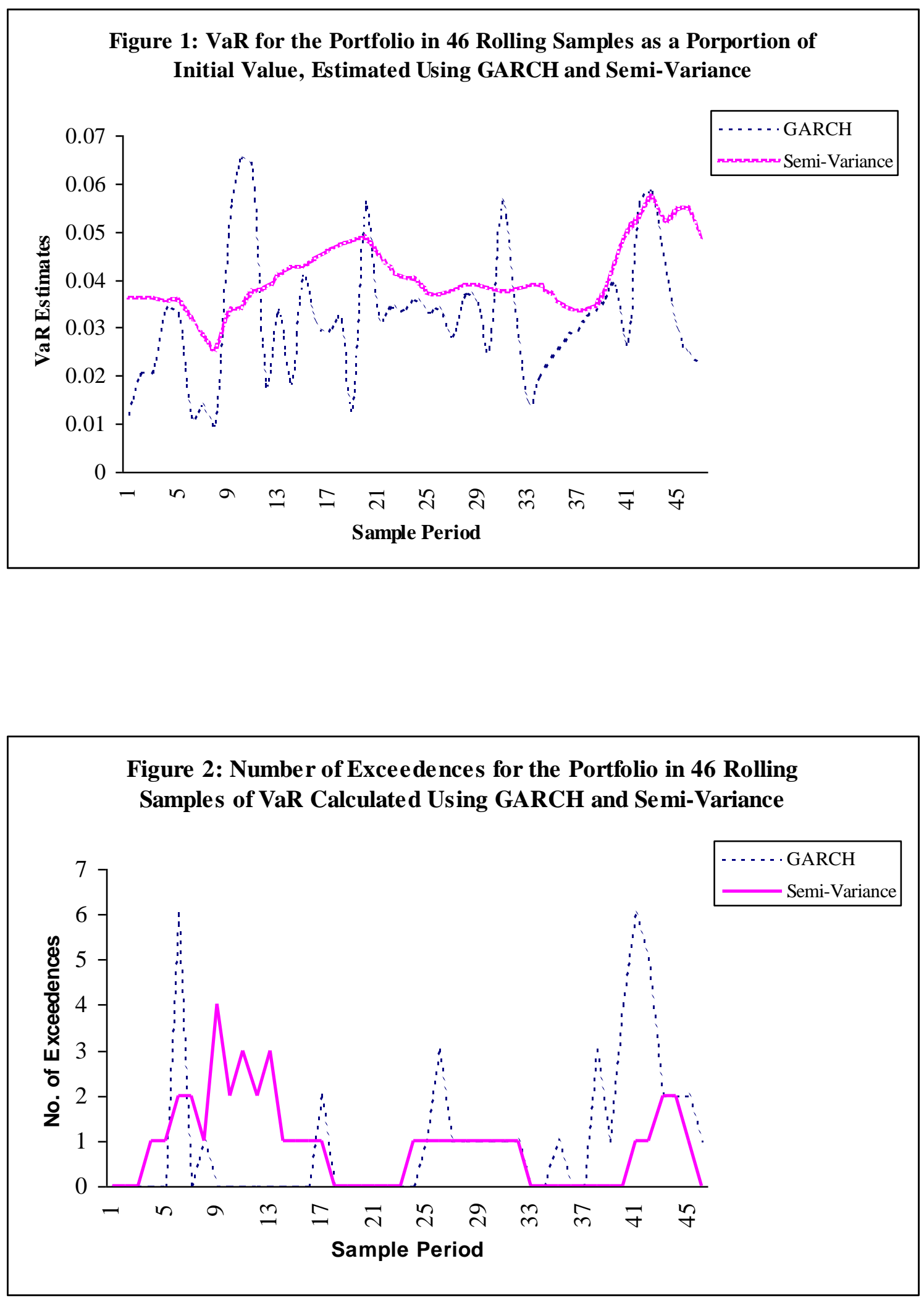